\title{
ASSESSMENT OF ORAL HEALTH QUALITY OF LIFE IN PATIENTS WITH HEMATOLOGICAL DISORDERS IN SAUDI ARABIA: PARENTAL PERCEPTION
}

\author{
Khalid Al-Johani* and Eman El Ashiry **
}

\begin{abstract}
Objective: This study aimed to evaluate the parental perception of the OHRQOL among a group of pediatric patients with hematological disorders and to assess the relationship between the oral health status of pediatric patients with hematological disorders. and their parents' perception of their OHRQOL.

Methods: The QoL of 100 children aged (6-12 years) was assessed using (Franciscan Hospital for Children Oral Health-Related Quality of Life (FHC-OHRQOL) through questionnaire filled by their parents. Oral examination was conducted on children assessing dental caries according to WHO, the oral hygiene according to the Simplified Oral Hygiene Index (OHI-S).

Results: $90 \%$ of the of parents reported that their children never and rarely suffered from oral related daily problems. Also, $93 \%$ of them rated their child as excellent and good when answering section IV of the OHRQOL to assess their perceptions of their child's oral well-being and overall QOL which not concomitant to the results of the oral examination. Also, results of the Simplified Oral Hygiene Index (OHI-S) revealed that children rated by parents as excellent and good scores which falls into the poor oral hygiene index (poor if the score was $>2$ ).

Conclusion: The results of the study showing that parents are unaware of the severity of the child oral condition and unable to correctly relate this to daily problems affecting the child quality of life. Raising the awareness towards oral health and its effect on the QoL is essential step to enhance their OHRQoL followed by prevention, screening and early detection of oral symptoms and problems.
\end{abstract}

\section{INTRODUCTION}

Oral health is a determinant of general health in addition to quality of life (Qol) of an individual. ${ }^{1}$ Heamatological disorders frequently affect soft and hard tissues of the mouth which can manifest in the orofacial area giving a characteristic clinical finding that may affect patients' daily activities (e.g. eating, swallowing) and/or appearance, figure (1) ${ }^{2-4}$.

* Oral Diagnostic Sciences Departement, Faculty of Dentistry, King Abdulaziz University, Jeddah, Saudi Arabia.

** Pediatric Dentistry Departement, Faculty of Dentistry, King Abdulaziz University, Jeddah, Saudi Arabia. and Pedodontic Department, Faculty of Dental Medicine for Girls , El Azhar University, Cairo, Egypt. 
Saudi Arabia is well-known for its high prevalence of hereditary blood disorders (sicklecell disease and $\beta$ - thalassemia). In Saudi Arabia, $4.20 \%$ had sickle cell trait, $0.26 \%$ had sickle cell disease, and $3.22 \%$ had $\beta$ - thalassemia trait, while $0.07 \%$ had had $\beta$-thalassemia disease. Certain cultural factors in Saudi Arabia, including the high frequency of consanguineous marriages (exceeding $55 \%$ ) and the large family size may contribute to the high prevalence of sickle-cell disease and $\beta$ thalassemia in Saudi Arabia. Because of the burden on the healthcare system and effect on the quality of life in patients with sickle-cell disease or $\beta$ thalassemia, it need proper preventive actions and early intervention, many of these disorders and their complications could, to a large extent, be eliminated. ${ }^{5}$ Oral health-related quality of life (OHRQoL) defined as "a multidimensional construct that reflects among other things, people's comfort when eating, sleeping, and engaging in social interaction; their self-esteem; and their satisfaction with respect to their oral health" ${ }^{6}$.

Some of the OHRQOL instruments were developed specifically for children. Children sometimes cannot answer questionnaires if they are either too young or too ill. In such situations the parents/ caregiver can be the best person to evaluate the OHRQOL of a child. A study done at the Franciscan Hospital in Boston, Massachusetts aimed to measure parents' perception of their children's oral health through developing a tool termed the Franciscan Hospital for Children Oral Health-Related Quality of Life (FHC-OHRQOL). This questionnaire described children's oral symptoms and problems related to these symptoms by their parents. It addressed the parent's concerns related to the oral health of their children with special health care needs and how effective oral health rehabilitation under general anesthesia was ${ }^{7}$.

There is little information available concerning the impact of hematological diseases upon oral health and their impact on the QoL of the affected individuals, therefor the present study aimed to assess parental perception of the OHRQOL of their children, identify the oral health status among patients with hematological disorders in Saudi Arabia as well as explore the effect of these disorders on the quality of life (QoL) of affected patients.

\section{OBJECTIVES}

- To evaluate the parental perception of the OHRQOL among pediatric patients with hematological disorders.

- To assess the relationship between the oral health status of pediatric patients with hematological disorders and their parents' perception of their OHRQOL.

\section{MATERIALS \& METHODS}

It is a descriptive cross-sectional study. It involved a group of children with hematological disorders. The QOL of the children was assessed using the FHC-OHRQOL. The oral health was assessed for the children in terms of: dental caries and oral hygiene.

The proposed study was approved by the Research Ethics Committee" of the Faculty of Dentistry at King Abdulaziz University.

\section{Inclusion Criteria:}

- Diagnosed and confirmed with hematological disorders and free from any other medical condition.

- Patients age between 6-12 years old

- Patient whom their parents approved to participate in the study.

\section{Exclusion Criteria:}

- Patient age younger than 6 and older than 12 years old 
- Patient whom their parents refused to participate in the study.

A total of 100 children (58 male and 42 female) with a mean age of 8 years (range of 6-12 years) were enrolled in the present study. According to medical history, $85 \%$ of the present cohort were diagnosed sickle cell disease patients and $15 \%$ were thalassemic patients

\section{OHRQOL}

The OHRQOL was determined using the FHCOHRQOL questionnaire.? This instrument was published in English, and was translated to Arabic in previous study. ${ }^{8} 9$ This instrument included 41 questions to assess the parental perception of the OHRQOL of their children. The questionnaire was originally developed by Ferrer with an aim of describing symptoms of children with special health care needs, daily life problems and concerns related to oral health needs. Also, the questionnaire looked into the effectiveness of oral rehabilitation performed under general anesthesia and how it improved quality of life. The FHC-OHRQOL consisted of 4 sections and each item was rated on a 4-point scale: never (0); hardly ever (1); some of the time (2) or all of the time (3). Section-I titled "child's oral problems/symptoms consists of 15 items. In this section the parents were asked to rate their children's current oral problems/symptoms including: spontaneous toothache, pain with hot or cool foods, pain with chewing, bad taste or bad breath, pain with sweets, bleeding with brushing or flossing, pain for no reason, broken teeth, dry mouth, painful bleeding gums, mouth sores, mouth blisters, swelling of the face, sore jaw, and headaches. Section-II titled, "your child's daily life," contained 13 items where the parents were asked to rate the impact of their children's current oral health on their daily lives (i.e. "does your child have difficulty getting to sleep because of tooth/mouth pain?"). The items in this section were: difficulty eating, acts irritable, refuses certain foods, difficulty getting to sleep, wakes up from sleep, acts aggressive, difficulty paying attention, behavior trouble, avoids meeting people, misses school, experiences jokes about teeth, avoids smiling because of ugly teeth and avoids smiling because of missing teeth. Section-III titled "parental concerns" consisted of 9 questions related to the parents' concerns about their children's oral health (i.e. "how often do you feel worried about your child's teeth or mouth interfering with their eating and nutrition?"). The items in this section were: eating and nutrition, anger about oral problems, schoolwork and attendance, missing sleep, parent missing work, change family plans, disrupt family life, unfinished chores and interferes with friendships.

In section-IV, a 13-cm visual analog scale (VAS) was used to answer each one of the 4 questions. The questions were:

1. What is your opinion of the appearance of your child's teeth and mouth?

2. How do you think your child's oral health is compared to other individuals of the same age?

3. How do you feel about your child's overall oral well-being?

4. How would you rate your child's overall QOL?

The VAS was constructed with "excellent" and "poor" at the ends of the scale and "good" in the center for questions 1, 3, and 4. For question 2, the VAS was anchored with "better than others his/ her age" and "much worse than others his/her age" with "about the same as others his/her age" in the center. Parents were instructed to mark the answer on the copy of the questionnaire that was provided for them after the examination and to return it with the child the

\section{Oral examination}

Oral examination on children assessing the teeth and the oral hygiene was conducted by two calibrated examiners. The inter-examiner reliability 
and the intra-examiner reliability was assessed and revealed strong agreement (0.998).

A flashlight was used to enhance visibility and disposable mirrors and gauze were used to facilitate the examination. To ensure the safety of the children all examinations were visual, and no probes were used.

The dental caries was determined according to $\mathrm{WHO}^{10}$ using the decayed, missing, filled teeth index (DMFT) for permanent dentitions and the decayed, filled teeth index (dft) for primary dentitions. The caries levels were categorized as very low (0-1.1), low (1.2-2.6), moderate (2.7-4.4), high (4.5-6.5) or very high (>6.6).16

The oral hygiene was determined according to the Simplified Oral Hygiene Index (OHI-S). ${ }^{11}$ the amounts of (debris or calculus) were recorded separately in the examination sheet and the Oral hygiene was considered good when the score was from 0-0.9, fair if the score was from 1-1.9 and poor if the score was $>2$.

\section{Statistical Analysis}

The anonymous patients' data were numerically coded and entered into the Statistical Package for Social Science (SPSS) version 22 (SPSS Inc,
Chicago, IL, USA) database. Significance was set at $\mathrm{p}<0.05$.

\section{RESULTS}

\section{Assessment of parent's perceptions of their child's oral well-being and QOL.}

Tables 1,2,3 \& 4 expresses the relationship between the intra-oral indices scores and the scores in section IV of the FHC-OHRQOL questionnaire.

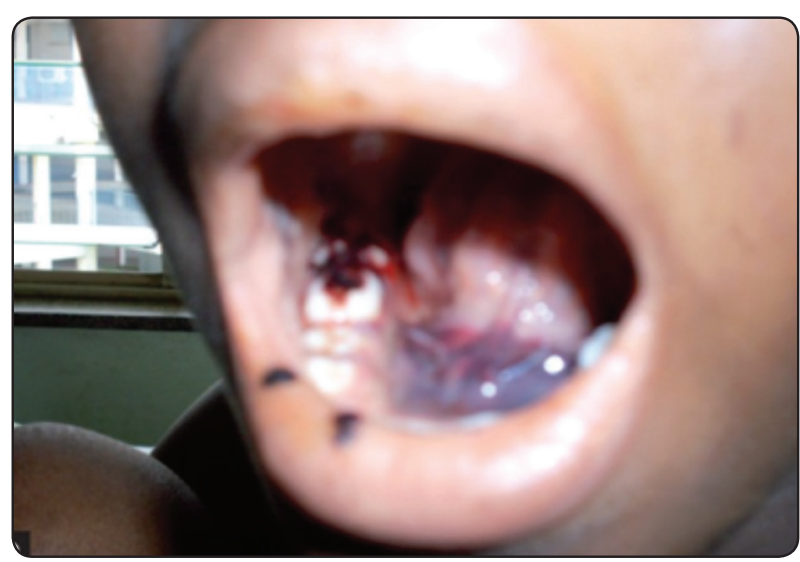

Fig. (1). Example of ecchymosis of the lower lip \& sublingual hematoma in a child with hematological disorder.

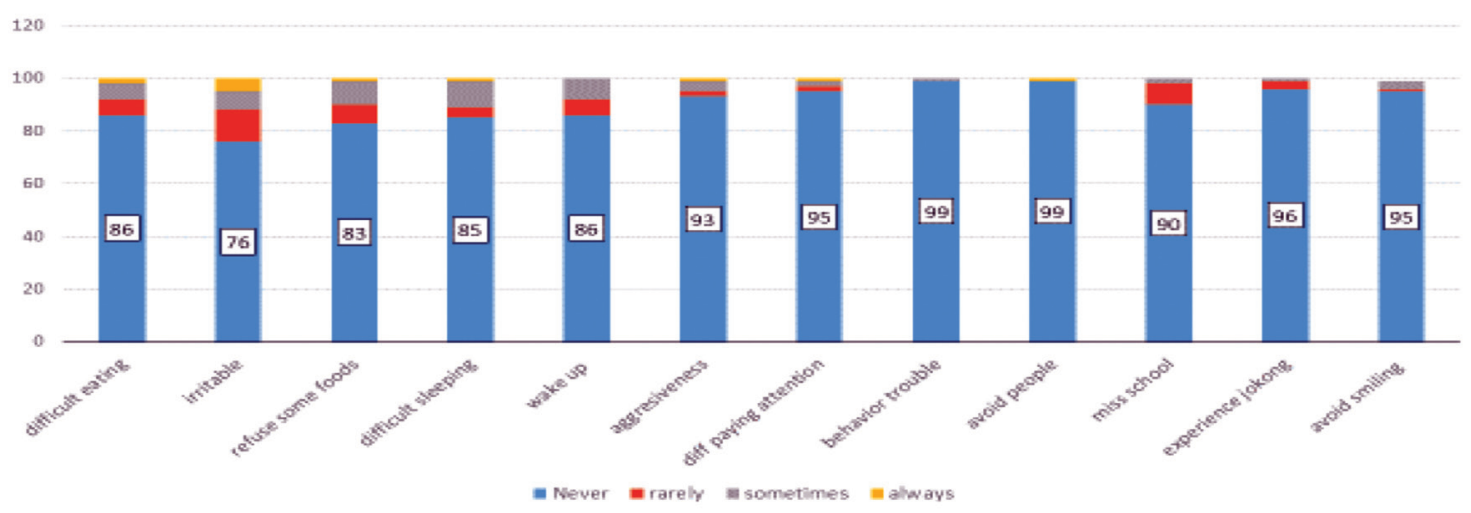

Fig. (2) Demonstrates the parents rating of the impact of their child's current oral health on their daily life namely difficult in eating, irritability, refusing to eat certain types of food, difficulty in sleeping, waking up at night, aggressiveness, difficulty paying attention, avoiding people, experience joking about the oral condition, missing school and avoiding smiling. Parents reported never in $76 \%$ to $99 \%$ of the daily life problems. 
TABLE (1) Dental caries index was statistically difference among the parent's opinion on the appearance of their children's teeth \& mouth ( $\mathrm{p}=0.000$ ), while there was no statistically significant relationship with the $\mathrm{OH}$ Index (Debris \& Calculus) and the gingival health scores.

\begin{tabular}{|c|c|c|c|c|c|}
\hline \multicolumn{6}{|c|}{ 1. What is your opinion of the appearance of your child's teeth and mouth? } \\
\hline Oral Symptoms & Parent opinion & $N$ & Mean & Std Deviation & $P$-value ${ }^{*}$ \\
\hline \multirow{4}{*}{$\begin{array}{c}\text { Dental Caries } \\
\text { Index }\end{array}$} & Poor & 7 & 4.00 & 3.606 & \\
\hline & Good & 52 & 3.77 & 3.934 & \\
\hline & Excellent & 41 & 3.59 & 3.821 & 0.000 \\
\hline & Total & 100 & 3.71 & 3.830 & \\
\hline \multirow{4}{*}{$\begin{array}{c}\text { OH Index } \\
\text { (Debris Index) }\end{array}$} & Poor & 7 & 3.29 & 2.498 & \\
\hline & Good & 52 & 2.73 & 2.394 & \\
\hline & Excellent & 41 & 2.37 & 2.374 & 0.090 \\
\hline & Total & 100 & 2.62 & 2.382 & \\
\hline \multirow{4}{*}{$\begin{array}{c}\text { OH Index } \\
\text { (Calculus Index) }\end{array}$} & Poor & 7 & .14 & .378 & \\
\hline & Good & 52 & .06 & .235 & \\
\hline & Excellent & 41 & .03 & .158 & 0.591 \\
\hline & Total & 100 & .05 & .220 & \\
\hline \multicolumn{6}{|c|}{$*$ Is significant when $p<0.05$} \\
\hline
\end{tabular}

TABLE (2) Dental caries index was statistically difference among the parent's opinion on the child's oral heath compared 10 oiher children $(\mathrm{p}=0.000)$, while there was no significant relationship with the OH Index (Debris \& Calculus) \& the Gingival Health scores.

\begin{tabular}{|c|c|c|c|c|c|}
\hline \multicolumn{6}{|c|}{ 2. How do you think your child's oral health compares to other children of the same age? } \\
\hline Oral Symptoms & Parent opinion & $N$ & Mean & Std Deviaton & $P$-value ${ }^{*}$ \\
\hline \multirow{4}{*}{ Dental Caries Index } & Poor & 15 & 7.67 & 5.010 & \\
\hline & Good & 55 & 3.16 & 3.060 & \\
\hline & Excellent & 30 & 2.73 & 3.300 & 0.000 \\
\hline & Total & 100 & 3.71 & 3.830 & \\
\hline \multirow{4}{*}{$\begin{array}{c}\text { OH Index } \\
\text { (Debris Index) }\end{array}$} & Poor & 15 & 2.73 & 2.434 & \\
\hline & Good & 55 & 2.84 & 2.339 & \\
\hline & Excellent & 30 & 2.17 & 2.451 & 0.459 \\
\hline & Total & 100 & 2.62 & 2.382 & \\
\hline \multirow{4}{*}{$\begin{array}{c}\text { OH Index } \\
\text { (Calculus Index) }\end{array}$} & Poor & 15 & .07 & .258 & \\
\hline & Good & 55 & .05 & .229 & \\
\hline & Excellent & 30 & .03 & .186 & 0.883 \\
\hline & Total & 100 & .05 & .220 & \\
\hline
\end{tabular}


TABLE (3) dental caries index was statistically difference among the parent's opinion about the child overall oral well-being ( $\mathrm{p}=0.000$ ), while there was no significant relationship with the $\mathrm{OH}$ Index \& the Gingival Health scores.

\begin{tabular}{|c|c|c|c|c|c|}
\hline \multicolumn{6}{|c|}{ 3. How do you feel about your child's overall oral well-being? } \\
\hline Oral Symptoms & Parent opinion & $\mathrm{N}$ & Mean & Std Deviation & $\mathrm{P}$-value* \\
\hline \multirow{4}{*}{ Dental Caries Index } & Poor & 24 & 7.04 & 4.369 & \\
\hline & Good & 56 & 3.11 & 3.108 & \\
\hline & Excellent & 20 & 1.40 & 2.162 & 0.000 \\
\hline & Total & 100 & 3.71 & 3.830 & \\
\hline \multirow{4}{*}{$\begin{array}{c}\text { OH Index } \\
\text { (Debris Index) }\end{array}$} & Poor & 24 & 2.75 & 2.152 & \\
\hline & Good & 56 & 2.96 & 2.537 & \\
\hline & Excellent & 20 & 1.50 & 1.906 & 0.057 \\
\hline & Total & 100 & 2.62 & 2.382 & \\
\hline \multirow{4}{*}{$\begin{array}{c}\text { OH Index } \\
\text { (Calculus Index) }\end{array}$} & Poor & 24 & .08 & .282 & \\
\hline & Good & 56 & .05 & .227 & \\
\hline & Excellent & 20 & .00 & .000 & 0.466 \\
\hline & Total & 100 & .05 & .220 & \\
\hline
\end{tabular}

*Is significant when $p<0.05$.

TABLE (4) No significant relationship between the Dental Caries Index ( $\mathrm{p}=0.954)$, OH Index (Debris/ Calculus) \& the Gingival Health scores according to the parents opinion on the overall QOL

\begin{tabular}{|c|c|c|c|c|c|}
\hline \multicolumn{6}{|c|}{ 4. How would you rate your child's overall QOL? } \\
\hline Oral Symptoms & Parent opinion & $N$ & Mean & Std Deviation & $P$-value $*$ \\
\hline \multirow{4}{*}{ Dental Caries Index } & Poor & 7 & 4.00 & 3.606 & \\
\hline & Good & 52 & 3.77 & 3.934 & \\
\hline & Excellent & 41 & 3.59 & 3.821 & 0.954 \\
\hline & Total & 100 & 3.71 & 3.830 & \\
\hline \multirow{4}{*}{$\begin{array}{c}\text { OH Index } \\
\text { (Debris Index) }\end{array}$} & Poor & 7 & 3.29 & 2.498 & \\
\hline & Good & 52 & 2.73 & 2.394 & \\
\hline & Excellent & 41 & 2.37 & 2.374 & 0.574 \\
\hline & Total & 100 & 2.62 & 2.382 & \\
\hline \multirow{4}{*}{$\begin{array}{c}\text { OH Index } \\
\text { (Calculus Index) }\end{array}$} & Poor & 7 & .14 & .378 & \\
\hline & Good & 52 & .06 & .235 & \\
\hline & Excellent & 41 & .03 & .158 & 0.406 \\
\hline & Total & 100 & .05 & .220 & \\
\hline
\end{tabular}

*Is significant when $p<0.05$. 


\section{DISCUSSION}

This research is a cross-sectional study addressing the oral health and OHRQOL in children with hematological disorders from the parents' perspective. This was achieved by conducting a brief oral examination on the children with hematological disorders and by the use of the FHC-OHRQOL as filled by parents.

The FHC-OHRQOL was chosen specifically because it was designed, and had been previously used on children with special needs, including children with hematological disorders. Very few researches were found concerning OHRQOL in children with hematological disorders in Saudi Arabia. The studies that were found mainly focused on the oral health status of these children ${ }^{12-14}$.

Reviewing data from this study revealed that around $90 \%$ of the of parents reported that their children never and rarely suffered from oral related daily problems (fig 2). Also, 93\% of them rated their child as excellent and good when answering section IV of the OHRQOL (tables 1,2,3 and4) to assess their perceptions of their child's oral wellbeing and overall QOL. This was not concomitant to the results of the oral examination, which showed that dental caries index for children in the excellent and good parent rating (ranging from 2.73 to 3.77 ) was always in the moderate level according to the WHO dental caries index. ${ }^{10}$ Moreover, results of the Simplified Oral Hygiene Index (OHI-S) ${ }^{11}$ revealed that children rated by parents as excellent and good scores ranged from 2.17 to 2.96 which falls into the poor oral hygiene index (poor if the score was $>2$ ). This shows that parents are unaware of the severity of the child oral condition and unable to correctly relate this to daily problems affecting the child quality of life.

Hematological disorders frequently affect soft and hard tissues of the mouth which can manifest in the orofacial area giving a characteristic clinical finding that may affect patients' daily activities eating, swallowing and appearance ${ }^{2-4}$. However, the study results revealed that $93 \%$ of the parent are unaware with the actual condition of the teeth and oral health of their children. This may be explained by the impression that the parents of children with hematological disorders were exhausted as care givers to children with this condition - and were more concerned and overwhelmed with their child's medical condition. Although the poor oral condition of the children in the current study could be attributed to the oral structural physiological changes that take place in patients with hematological disorders, still, low priority is given to the basic preventive dental care for these children .

Many studies concluded that children with hematological disorders could be able to have better OHRQOL by improving their oral hygiene level and regularly visiting the dental office. ${ }^{15-17}$. The awareness of the importance of oral heath as a part of general health is becoming widespread..$^{18}$ However, dental care remains the most common unmet health care need. ${ }^{19,20}$

Parents of hematological disorders children are preoccupied with main life-threatening problem 4, and more efforts are required from the treating physician to adopt a holistic approach where oral health is considered and integrated aspect of the standardized care management. Working in a team with medical colleagues is a very enriching experience and educational for both parties. Involving medical colleagues is of paramount importance together with establishing a good referral system that emphasize involving parents in oral health education programs that ensure preventive and early case finding skills, to enhance the patient quality of life.

\section{CONCLUSION}

- The results of the study showing that parents are unaware of the severity of the child oral condition and unable to correctly relate this to daily problems affecting the child quality of life. 
- Raising the awareness towards oral health and its effect on the QoL is essential step to enhance their OHRQoL followed by prevention, screening and early detection of oral symptoms and problems.

- PLANED strategies for oral hygiene educational and preventive programs should be implemented among parents and caregivers of children with hematological disorders

\section{REFERENCES}

1. Petersen PE. The World Oral Health Report 2003: continuous improvement of oral health in the 21st century - the approach of the WHO Global Oral Health Programme. Community Dent Oral Epidemiol [Internet], 2003.

2. Smit Singla, Akhilesh Verma, Snehil Goyal, tika Singla. Oral Manifestations of Hematological Disorders - Rbc Diso. IJRID. 2014; 4 (4).

3. Sambandan T. Review on oral manifestations of blood diseases. JIADS 2010;1(4).

4. Titilope A Adeyemo, Wasiu L Adeyemo, Adewumi Adediran, Abd Jaleel A Akinbami, Alani S Akanmu. Orofacial manifestations of hematological disorders: Anemia and hemostatic disorders. IJDR.2011; 22(3):454-61.

5. Shehab Ahmed Alenazi, Hafeezullah Wazir Ali, Mohammed Ghannam Alharbi, et al. Prevalence of Thalassemia and Sickle Cell Disease in Northern Board Region of Saudi Arabia. Kashmir J Med Sci. 2015;1(1).

6. U.S. Dept of Health and Human Services. Oral health in America: A report of the Surgeon General. NIH Publication 2002; 00-4713. Rockville, Maryland: National Institute of Dental and Craniofacial Research, National Institutes of Health.

7. Beans-Ferrer C, Roseman MM, Dumas HM, Haley SM. Parental perception of oral health-related quality of life for children with special needs: impact of oral rehabilitation under general anesthesia. Pediatr Dent .2005;27: 137-142

8. Sumer M. Alaki, Jihan A. Khan, Eman A. El Ashiry. Parental Perception of Oral Health Related Quality of Life in Children with Autism Advances in Environmental Biology. 2016; 10(12): 213-221.
9. Eman A El Ashiry, Sumer M Alaki, Sumaya M Nouri. Oral Health Quality of Life in Children with Cerebral Palsy: Parental Perceptions. J Clinic Pediatr Dent. 2016; $40(5)$.

10. World Health Organization, 1997. Oral Health Surveys: Basic Methods, ed 4. Geneva, WHO.

11. Greene, J.C., J.R. Vermillion, 2011. The Simplified Oral Hygiene Index. Journal of American Dental Association, 68: 7-13.

12. Alamri MH, Alqahtani RA, Alqahtani NA, Shobeili WA, Togoo RA, Zakirulla M. Oral health status and treatment needs of children with sickle cell disease in Abha and Khamis Mushait cities of southern Saudi Arabia. Int J Res Med Sci. 2018; 6:431-437.

13. Jokovic A, Locker D, Tompson B, Guyatt G. Questionnaire for measuring oral healthrelated quality of life in eight- to ten-year-old children. Pediatr Dent. 2004; 26: 512-8.

14. Seid M, Varni JW, Segall D, Kurtin PS. Health-related quality of life as a predictor of pediatric healthcare costs: A two-year prospective cohort analysis. Health Qual Life Outcomes. 2004;2:48.

15. Qureshi A, Chadhry S, Alam M, Izhar F, Ali Khan A. Is oral health status of children with $\beta$-thalassemia worse than that of their normal counterparts? JKCD 2010;1: 4-7.

16. Pedulla E, Scibilia M, Saladdino G, Colletta G, Rapisarda $S$, et al. Dental and periodontal condition in patients affected by $\beta$-thalassemia major and $\beta$-thalassemia intermedia: A study among adults in Sicily, Italy. J Dent Heal Oral Disord Ther.2015; 3: 1-5

17. Phrai-in N, Noikeaw J, Sukprasert N, Taya T, Samnieng P. Oral health status and impact on oral healthrelated quality of life in children with thalassemia major. UIP Heal MED.2016; 1: 144-146

18. Al-Shehri S. Access to dental care for persons with disabilities in Saudi Arabia (caregiver's perception). Journal of Disability and Oral Health.2012; 13: 51-61.

19. Lewis CW. Dental care and children with special health care needs: population-based perception. Acad Pediatr.2009; 9: 420-426.

20. Weil TN, Inglehart MR . Dental education and dentists' attitudes and behavior concerning patients with autism. J Dent Educ.2010; 74: 1294-1307. 